\title{
PATRICIA CRAVIOTTO VALLE: CONSECUENCIAS DE LA QUIEBRA DEL DERECHO A LA SALUD. REGULACIÓN DE LA EUTANASIA: UN DERECHO SIN RESPALDO JURÍDICO.
}

\section{CONSEQUENCES OF THE FAILURE OF THE RIGHT TO HEALTH. REGULATION OF EUTHANASIA: A RIGHT WITHOUT LEGAL BACKING.}

RESUMEN: La salud es uno de los estados de la persona y suele relacionarse con la mejor o peor situación física y/o psíquica de las mismas. El derecho a la salud hace referencia al mejor estado posible. Pero ¿qué ocurre cuando la salud es todo lo contrario? Cuando la salud es pésima e incluso únicamente puede empeorar, se quiebra este principio del derecho. ¿Qué nos queda entonces?

ABSTRACT: Health is one of the states of the person and is often associated with better or worse physical and/or mental state of the same. The right to health refers to the best possible condition. But what happens when health is the opposite? When health is bad and even can only worsen, this principle of bankruptcy law. What remains then?

PALABRAS CLAVE: Derechos fundamentales. Ciencia biomédica. Derecho a la salud. Eutanasia. Moral y ética. Libertad de elección. Dignidad. Responsabilidad. Muerte digna.

KEY WORDS: Fundamental rights. Biomedical science. Right to health. Euthanasia. Moral and ethical. Freedom of choice. Dignity. Responsibility. Dignified death.

Siendo puristas lingüísticamente y basándonos en el rigor que nos conceden las palabras, la salud se nos presenta como el "estado en que el ser orgánico ejerce normalmente todas sus funciones, o el conjunto de las condiciones físicas en que se encuentra un organismo en un momento determinado" ${ }^{\prime \prime}$.

Así pues habremos de convenir que al igual que ocurre con la suerte, la salud se nos presentará en una escala gradual que variará desde la excelencia a la decadencia, y viceversa. La salud-por tanto- no hace referencia en exclusiva a

\footnotetext{
${ }^{1}$ Definición de "salud" según la Real Academia de la Lengua Española: R.A.E.
} 
las óptimas condiciones de funcionamiento de los seres vivos: salud también comprende el fallo de esas funciones. Por ello tanto en el ámbito de la Bioética como en el del Derecho, ni se debe obviar esta dualidad de situaciones opuestas, ni deben olvidarse los diferentes grados salubres que conllevan en sí las enfermedades. Así será más sencillo entender que el derecho a la salud, hemos de visualizarlo en esta doble perspectiva: la buena salud y la mala salud. Bondades y carencias. Beneficios y perjuicios. Consecuencias positivas y negativas. Vida y -llegado el caso- muerte.

El derecho a la salud es un derecho universalmente reconocido ${ }^{2}$ y a su vez ligado a otros tales como el derecho al bienestar, alimentación, vivienda, vestido, asistencia médica, educación, trabajo,... Puede entonces deducirse y afirmarse que el estado de salud de las personas es susceptible de modificación a lo largo de sus vidas, en función de variables tales como el tipo de alimentos que consuman, el abrigo y cobijo del que dispongan, el mayor o menor acceso a la asistencia médica, y otras muchas circunstancias entre las que no cabe olvidar el mimo y cuidado que cada ser humano preste a su propio cuerpo y mente.

A todo ello habremos de añadir que la dependencia de la salud no solo es responsabilidad del ser humano en sí mismo, sino que variará en función de su entorno social, económico, político, medioambiental, etc. Por lo que deberemos estar atentos a otras posibles causas que modifiquen su calidad humana, con independencia de los mismos.

En este momento hemos de prestar especial atención a los Estados, a las instituciones públicas y por qué no, a las empresas. Vivir en una gran ciudad o en una pequeña población puede definir -y a su vez alterar- la salud de las personas. Por ejemplo acceder y consumir a gran variedad de alimentos o por el contrario carecer de acceso a los mismos, puede hacer estragos en la salud personal. Igualmente los ritmos de trabajo en sociedades muy desarrolladas, los hábitos de sueño, los tipos de familia,...pueden modificarla -mutarla-, ya sea para su beneficio o su perjuicio.

Las decisiones que toman los Estados -habitualmente de carácter paternalista en busca del bien común ${ }^{3}$-, acaban reflejados en normas -que por su propia idiosincrasia-, serán de obligado cumplimiento. Luego la prohibición o la promoción de ciertas industrias, la decisión de crear o no obras hidráulicas, las

\footnotetext{
${ }^{2}$ Declaración Universal de Derechos Humanos: adoptada y proclamada por la Asamblea General en su resolución 217 A (III), de 10 de diciembre de 1948. Art. 25.1: "Toda persona tiene derecho a un nivel de vida adecuado que le asegure, así como a su familia, la salud y el bienestar, y en especial la alimentación, el vestido, la vivienda, la asistencia médica y los servicios sociales necesarios;...."

3 "El Bien Común no es un bien colectivo que se imponga sobre los bienes personales (vida, salud, dignidad de la persona...), sino que lo trasciende. Sin embargo, es evidente que tiene una superioridad sobre los bienes individuales habituales (propiedad, derechos civiles, etc.), aunque no los excluya necesariamente. De hecho el Bien común exige que cada uno tenga su bien particular". Fines y límites del Estado: paternalismo y libertades individuales. Jose Carlos Abellán Salort. Universidad Francisco de Vitoria.
} 
limitaciones en el libre mercado ${ }^{4}$-exportaciones e importaciones-, etc., podrán variar con toda seguridad la salud de las personas, de los ciudadanos.

Nos vemos así abocados a considerar válida la siguiente afirmación: la salud de las personas no depende en exclusiva de ellas mismas.

Llegados a este punto, si reflexionamos acerca del derecho a la salud nos preguntaremos, qué significa en esencia poder disfrutar de este derecho per se.

Queda meridianamente claro que equivale a poder disfrutar de -entre otras cuestiones- una vivienda digna, una buena alimentación, una correcta atención sanitaria, una vida tranquila y en paz,......adjetivos todos ellos positivos y beneficiosos: digna, buena, correcta, tranquila, pacífica. Pero la realidad es que hoy no estaríamos preocupados e invirtiendo nuestro tiempo en estas cuestiones, si no fuese porque la salud no siempre es buena, ni digna. ¿Qué ocurre entonces con el derecho a la salud?

Si la salud de las personas se refleja en un grado que puede oscilar desde la cuasi perfección del funcionamiento orgánico, a la más pantanosa de las situaciones en las que el cuerpo y/o la mente pueden verse abocados al desastre, ¿disfrutaremos ese derecho en cualquier caso? ¿Solo cuando esta sea benigna, beneficiosa, digna o pacífica? ¿Qué ocurre cuando la salud se torna maligna, perjudicial, contagiosa o indigna? ¿Debemos continuar estimando tener derecho a ella a pesar de que haya elementos externos determinantes de la misma, no susceptibles de ser dirigidos o reconducidos por la propia persona? ¿Podríamos en este último caso seguir analizando el derecho a la salud como hasta ahora lo hemos entendido?

Planteadas y meditadas estas cuestiones, tiene sentido común comenzar a modificar la perspectiva que tenemos hacia este derecho, pues defiende con fortaleza la ética y la moral que tiende a la mejora de la salud. Pero francamente se nos queda corta la visión desde el momento en que esta se vuelve irresoluble, decadente y por qué no, inhumana. Hemos asumido las enfermedades e incluso la muerte, pero no hemos conseguido visualizar el derecho a la enfermedad ${ }^{5}$.

Con total seguridad existirán límites a partir de los cuales habremos de ser prudentes. Pero deberemos partir del reconocimiento de todos los derechos de las personas que sin salud, ya no volverán a tenerla jamás -si es que alguna vez llegaron a poseerla-.

Parece existir únicamente el derecho a sentirse bien, a tener buena salud. A exigirla incluso. Pero ¿qué ocurre con aquellas personas que se sienten mal pese a todo? ¿Aquellas personas que tienen mala salud o cuyo buen estado merma poco a poco, o de pronto por un mal golpe de azar?

\footnotetext{
${ }^{4}$ En la actualidad la salud de miles de venezolanos se ve afectada por decisiones tomadas por el Gobierno de la Nación. La salud no solo depende del propio ciudadano; también depende de la accesibilidad que tengan estos a los recursos de primera necesidad como alimentos, medicinas, etc.

${ }^{5}$ No debe confundirse con el "derecho del enfermo o del paciente".
} 
Podemos entonces afirmar sin temor a confusiones que hemos asumido la salud como un derecho a tener en cuenta a nivel mundial, pero sin embargo no se ha atendido como se merece el derecho a la enfermedad como parte fundamental de la vida y de los derechos humanos. Como aquel momento en el que la vida se acerca a su final, y la voluntad unilatera ${ }^{\beta}$ de la persona decide en qué preciso instante ha de llegar el mismo.

$Y$ este es el momento verdaderamente conflictivo -tanto en Bioética como en Derecho- respecto a las decisiones personales voluntarias que puedan tomarse en relación a cuándo y cómo morir. ¿Dónde está el límite de la voluntad de las personas para tomar dicho tipo de decisiones?

No es objetivo de quien les escribe, plantear debates sobre qué edades o enfermedades pudieran ser receptoras de este derecho. Tampoco si únicamente puede ser reclamado por la propia persona ${ }^{7}$ o podrían realizarla terceros ${ }^{8}$-como es el caso de niños enfermos cuyos padres suplican una muerte digna en los diferentes sistemas jurídicos existentes en la actualidad, a nivel internacional-.

Ante estas cuestiones analizaremos con detenimiento dos de los principios fundamentales en bioética: (i) el principio de autonomía y (ii) el principio de no maleficencia.

(i) Si el principio de autonomía parte de la libertad absoluta de la persona respecto a la toma de decisiones o realización de acciones sobre uno mismo, su antítesis no cabe duda de que es la heteronomía ${ }^{9}$. ¿Actualmente el Estado español permite al enfermo disfrutar al cien por cien de su derecho a decidir? $¿ E \mathrm{El}$ principio bioético y jurídico de la autonomía personal del enfermo respecto a la rotura de su salud, es real? La respuesta es contundente: no. Si así fuera, el derecho a la enfermedad y a la toma personal de decisiones estaría regulado en la actualidad, cosa que no ocurre en el Estado español.

(ii) Si el principio de no maleficencia se basa en la abstención intencionada de realizar actos que puedan causar daño o perjudicar a otros, ¿acaso no nos encontramos ante acciones que dañan o perjudican al enfermo, cuando mantenerle vivo es más perjudicial que beneficioso para él? La falta de regulación

\footnotetext{
${ }^{6}$ El derecho Civil español reconoce como Fuente de las Obligaciones, la Voluntad Unilateral. A pesar de no haber referencia alguna en el art. 1089 CC español, el hecho de que el Código Civil Alemán -BGB- dedicase un párrafo a la eficacia obligatoria de las promesas públicas de recompensa, hizo que nuestra doctrina se plantease esta circunstancia, admitiendo como fuente de obligaciones indiscutible la voluntad unilateral de las personas. Especialmente en el caso de los testamentos, acto mortis causa por excelencia.

7 Caso de la deportista paralímpica belga -Marieke Vervoort-, que anunció su solicitud de aplicación de la eutanasia, tras participar en los Juegos de Río de Janeiro 2016.

${ }^{8}$ Caso de la niña española de 12 años, cuyos padres -Antonio Lago y Estela Ordóñez- solicitaron una muerte digna para su hija Andrea. En octubre de 2015 el equipo médico accede a retirar la sonda de alimentación y con ello el soporte vital y los cuidados paliativos.

${ }^{9}$ Sometimiento a un poder externo. Que vive según reglas que le son impuestas.
} 
de este derecho natural ${ }^{10}$-toma de decisiones personalísimas-, ¿nos expone ante una rotura del principio de no maleficencia al causar daño o perjuicios por acción o por omisión? ¿No deberíamos -en ciertas situaciones-, abstenernos de causar estos daños evidentes? La respuesta también es contundente: la falta de regulación nos obliga a situarnos en una laguna jurídica donde cualquier realización de actos que aparentemente puedan beneficiar a las personas, lo único que consiguen es alargar agonías con la consecuente quiebra de dicho principio. Sin embargo no actuamos para evitar ese daño. En muchas ocasiones todo lo contrario: se mantiene durante un tiempo desesperante para enfermos, familiares y seres queridos.

Expone Norbert Bilbeny ${ }^{11}$ en relación al capítulo XIII de la obra de Erasmo de Rotterdam"12 -Elogio a la locura (1511)-, que "el bebé nace alegre, pero inconsciente, y el adulto, que ha ido perdiendo la alegría conforme se hace consciente, al final de sus días estaría sumido en la más absoluta desesperación si no fuera gracias a que va perdiendo la consciencia, también, y se vuelve en este aspecto como un niño. Deja de ser «autónomo», diríase hoy".

No deja de ser curiosa la idea de poder exportar de estos textos del siglo XVI el hecho de que el nacimiento y la muerte continúan teniendo grandes similitudes. Los recién nacidos y las personas moribundas -con independencia de la edad que tengan en ese momento-, se caracterizan por necesitar cuidados de otros: ya sea a través de la familia, de los amigos o de los profesionales sanitarios. Sin esta ayuda, sus vidas correrían un grave peligro: los niños por su absoluta falta de autonomía y capacidad, y los enfermos -moribundos- por idénticos motivos. La diferencia es que mientras los primeros no tienen consciencia, los segundos sí pueden tenerla -en la mayoría de casos-.

Esta reflexión se vuelve profunda e incómoda cuando observamos aquellos casos en los que la salud se torna enfermedad sin que sea posible su mejora. La salud se vuelve sórdida y enemiga al propio cuerpo y a la mente que lo habita. Los medios paliativos no son suficientes y la persona sufre hasta -a vecesextremos insoportables que simplemente $-\mathrm{y}$ con clara consciencia- no está dispuesta a seguir padeciendo en ningún caso. No quiere continuar por ese camino. Su voluntad es la de poner fin de manera unilateral a su situación personal, que a su vez implica a las personas más cercanas: especialmente familia. En estos casos en los que el Derecho no recoge los clamores de los

\footnotetext{
${ }^{10}$ El derecho natural -como doctrina ética y jurídica-, postula la existencia de los seres humanos, basados o determinados en su propia naturaleza. Proclama derechos universales previos $-\mathrm{y}$ superiores e independientes- al derecho positivo y al consuetudinario.

11 Nacido en Barcelona (1953), este Catedrático de ética de la Universidad de Barcelona y ensayista español, aporta su visión sobre la "autonomía heterónoma, al principio y al final de la vida" en el capítulo redactado para la obra conjunta "Bioética: la toma de decisiones".

12 Erasmo de Rotterdam (1466) era un humanista, filósofo, filólogo y teólogo, nacido en los Países Bajos. Fue autor de manuales, libros, cartas, etc., entre las que destacan obras como Manual del caballero cristiano (1503), una versión griega que él escribió sobre el Nuevo Testamento (Textus Receptus-1516), Elogio de la locura (1511), Sobre la enseñanza firme pero amable de los niños (1528), o Preparación para la muerte (1534).
} 
desesperados ¿qué les queda? ¿El suicidio? Y ¿qué ocurre con los que ni siquiera pueden realizar este acto llegado el caso? ¿La desesperación y la locura?

Tampoco es objetivo de este artículo tasar situaciones en las que el derecho a la enfermedad -a través de los principios axiológicos de la autonomía personal y la no maleficencia-, debería comenzar a ser tenido en cuenta en nuestro Estado de Derecho español. Pero como estudiosos del Derecho tenemos la responsabilidad de plantear sin prejuicios aquellas situaciones en las que las normas no han llegado a regular casos tan dolorosos, reales y actuales para el ser humano. Derechos que siendo reconocidos en otros Estados ${ }^{13}$-con su pertinente formulación técnica-, no son aplicables en el Estado español bien por falta de atención o por miedo a dar un paso -biológico y jurídico- que hasta hoy nunca se ha producido.

Nos encontramos ante una potencial situación jurídica que se resume en posibilitar actuaciones, antes de que suceda lo evidente. Tendríamos un mecanismo jurídico que permitiría poder decidir sobre la salud de uno mismo -o en su caso de las personas dependientes que le competan-.

Salvando las grandes diferencias existentes, encontramos similitud entre el derecho a la enfermedad -respecto a la salud-, y el derecho penal del enemigo ${ }^{14}$. a los derechos fundamentales-. Similitud en cuanto al momento, al espacio temporal que permitiría actuar antes de que un suceso inminente y seguro ocurra con toda probabilidad. En el caso que nos ocupa, atendemos a quienes padecen enfermedades incurables y dolorosas, largas, insoportables, indignas y aun así se les priva de su capacidad para planificar el fin de sus días. Del derecho a dejar de sufrir su enfermedad. Del derecho a morir en paz y con dignidad.

No olvidemos que el derecho del enfermo a decidir sobre la finalización de su vida, devendría en sanción penal en quien le ayudase a ello. No por la conducta en sí de ayuda, sino por la afectación del bien jurídico -la vida-, y la puesta en peligro de la misma -la muerte-.

No se discute que el derecho a la salud deba entenderse como el derecho fundamental que las personas adquieren desde su nacimiento, para acceder a los recursos necesarios que mejoren el desarrollo de sus vidas.

Pero las personas que carecen de salud también deben tener sus derechos, ya sea porque no tienen acceso a los recursos básicos e imprescindibles de los que hablamos, bien porque sus organismos se degradan encaminándose a la muerte de manera inminente, porque no exista una cura conocida y los medios paliativos sean ineficientes, porque su voluntad sea la de

\footnotetext{
${ }^{13}$ Holanda (2002), Bélgica (2002, ampliada en 2014 a menores), Luxemburgo (2008), Suiza (2006), Colombia (2015), EEUU (5 Estados).

${ }^{14}$ Salvando los diferentes asuntos en cuestión, Günther Jakobs hace referencia con la expresión "derecho penal del enemigo" a la sanción penal de conductas, no por la afectación del bien jurídico, sino por la puesta en peligro del mismo. Exportable ello a la situación analizada respecto a la salud.
} 
no continuar con esa carencia de salud, o por las infinitas variables posibles que pudieran darse y en las que no profundizaremos.

Todo lo tratado hasta ahora no entra en el ámbito de los derechos del paciente ${ }^{15}$, que fueron reconocidos jurídicamente a través de la Constitución Española en 1978 -artículo $43^{16}$. Actúa en el ámbito de quienes -siendo o no pacientes-, son enfermos cuya salud no obtendrá remedios bondadosos, no devendrán en una muerte digna, no tendrá una mínima calidad de vida, etc. Por ejemplo enfermedades incurables donde el dolor no es más que una pequeña parte de su composición. ¿Qué derecho tiene el enfermo a decidir sobre el final de su vida? ¿Cuál es el límite de su voluntad?

Si la quiebra de la salud puede conllevar inexorablemente consecuencias tan devastadoras en las personas, ¿estamos dispuestos a regular estas situaciones definitivamente en España? ¿Somos capaces -los juristas- de abstraernos de nuestras convicciones religiosas o morales para reconocer la omisión normativa y la invisibilidad de la que han sido pasto estas personas? (La soberbia, la arrogancia, es el complemento de la ignorancia ${ }^{17}$ ).

Dado que la que les escribe es jurista, debo remitirme a los aspectos éticos del ejercicio de mi profesión como abogada. De ahí que basándome en los principios de ética profesional jurídica ${ }^{18}$, me encuentre ante los Principios de Beneficencia $^{19}$-y No Beneficencia-, Justicia ${ }^{20}$, Responsabilidad ${ }^{21}$ y Autonomía $^{22}$.

${ }^{15}$ En España existe un amplio marco legal que comienza con el art. $43 \mathrm{CE}$, continúa con la Ley Básica Reguladora de la Autonomía del Paciente y de Derechos y Obligaciones en Materia de Información y Documentación Clínica -Ley 41/2002-, y es seguida por la Ley 16/2003 de Cohesión y Calidad del Sistema Nacional de Salud, por la Ley 33/2011, de 4 de octubre, General de Salud Pública, y por último se regulan en el Real Decreto-Ley 16/2012, de 20 de abril, importantes aspectos de las citadas normas anteriores: especialmente el derecho de los ciudadanos residentes a la atención sanitaria pública.

${ }^{16}$ Según el Art. 43 de la CE: 1. Se reconoce el derecho a la protección de la salud. 2. Compete a los poderes públicos organizar y tutelar la salud pública a través de medidas preventivas y de las prestaciones y servicios necesarios. La ley establecerá los derechos y deberes de todos al respecto. 3. Los poderes públicos fomentarán la educación sanitaria, la educación física y el deporte. Asimismo facilitarán la adecuada utilización del ocio.

17 "La actitud es esencial. La manera de mirar las cosas, y de cómo nos las contemos a nosotros mismos. A veces devendrán cosas malas.... Ios pensamientos son los que determinarán cómo vivir la vida. ....Serenidad para aceptar lo que uno no puede cambiar; valor para cambiar lo que hay que cambiar; y sabiduría para diferenciar ambas cosas". Marco Aurelio. Emperador romano y filósofo. (121-180 d.C.)

${ }^{18}$ Memento Práctico Francis Lefebvre. Acceso a la Abogacía. 2013-2014. Universidad Pontificia de Comillas. Ediciones Francis Lefebvre, S.A. Julio 2013. Madrid. Parte II. Capítulo 1. Ética de la abogacía.

${ }^{19}$ Significa "deber de hacer bien", en línea con la noción doctrinal-jurisprudencial de lex artis ad hoc, junto al canon de diligencia preceptuado en el art. 1104 CC.

${ }^{20}$ Justicia como el referente axiológico al que hace referencia Ulpiano en su obra Honeste vivere, como valor superior del ordenamiento jurídico. Justicia citada tras la libertad, pero antes que la igualdad y el pluralismo político. Justicia proyectada desde el lado de la dignidad humana (art. 10.1 $\mathrm{CE})$, como del lado de la igualdad (art. $14 \mathrm{CE}$ ). 
Mientras que la responsabilidad parte de la sensibilización y de la concienciación, la autonomía -subjetiva y personal como ha de ser en su intimidad jurídica-, requiere una consecución de fases en las que se habrán de suceder necesariamente en primer lugar, la reflexión seguida de la convicción y por último la decisión.

Analizado esto, me reafirmo en la idea de que jurídicamente el Principio de Autonomía presupone la libertad y apela a la subjetividad. Sin embrago y a pesar de no olvidar su función social -presente en todos los principios citados-, la normativa actual en el Estado Español es inexistente o muy limitada, careciendo así la "autonomía personal" de protección jurídica alguna.

Decíamos que el nacimiento y la muerte son los momentos de la vida que más se asimilan, pudiendo poner como referentes a un bebé recién nacido y a un anciano moribundo. Es por ello que el Principio de Autonomía es fundamental para reflexionar, convencerse y tomar decisiones, en ambas situaciones. La diferencia es que en el caso de los recién nacidos serán sus padres o tutores los que decidirán sus cuestiones de su salud -por incapacidad evidente del neonato-, y en el caso del moribundo podrá ser la propia persona -o en su caso su tutor-, quien deba realizar estas reflexiones previas para convencerse de que la decisión que debe adoptar es lo mejor para ella. Me refiero a la posibilidad -inexistente en la actualidad normativa Española- de tomar decisiones íntimas, personales, libres, voluntarias y autónomas, sobre cómo cerrar el último ciclo de vida en función de la propia salud, con el respeto y el reconocimiento que las normas jurídicas deben a estas situaciones personales límite. respecto:

En el caso de que consideremos necesario realizar una regulación al

i) ¿Qué mínimos requisitos o condiciones habrá de cumplir un enfermo para que pueda ser reconocida su capacidad de decisión en este ámbito?

ii) Las diferencias entre capacidad jurídica y capacidad de obrar, ¿deberán ser tenidas en cuenta en la supuesta regulación? Si se tiene capacidad jurídica pero no de obrar, ¿podrá decidir la persona? ${ }^{23}$

iii) ¿Qué ocurre con las personas con incapacidad jurídica -permanente o temporal? En este caso ¿quién es responsable de la decisión?

${ }^{21}$ Principio de Responsabilidad considerado como el reverso del Principio de Autonomía. Responsabilidad cobra virtualidad a través de un proceso en el que deberán estar presentes la sensibilización y la concienciación: ¿De qué soy responsable? ¿Ante quién soy responsable? ¿En virtud de qué soy responsable?

${ }^{22}$ Principio de Autonomía como máximo exponente de la dimensión subjetiva individual. Verificado este Principio a través de la triple secuencia: (i) reflexión, (ii) convicción, (iii) decisión.

${ }^{23}$ En España se dio el caso de Ramón Sampedro -marino y escritor-. Desde los 25 años, este señor sufría una tetraplejia y sin embargo desarrolló una intensa lucha judicial para poder morir. No tenía capacidad para obrar físicamente, por lo que pedía que quien le auxiliase -para finalizar su vida- no fuera considerado un delincuente. 
iv) Siendo el enfermo un menor de edad, ¿qué cualidades han de darse en su salud para que sus padres -o tutores- decidan por él?

Se vislumbran una serie de conflictos éticos, biológicos y jurídicos de gran calado. Pero el asunto en cuestión merece ser tratado y regulado a todas luces por la importancia del mismo.

Dice el Prof. Dr. Ignacio Arroyo Martínez ${ }^{24}$-tras cuarenta años de actividad docente y profesional-, que el Derecho en definitiva no es otra cosa que la ejecución de las sentencias dictadas por los jueces y tribunales, y no exactamente el conjunto de normas jurídicas - de obligado cumplimiento- que regulan los comportamientos humanos. Este concepto del Derecho me parece muy acertado, pues se impone la práctica real, a la teoría positivista -sin menospreciar o menoscabar la misma-. Ante un mismo supuesto de hecho, el derecho es aplicado con diferentes resultados en su ejecución.

Así me asalta la siguiente cuestión: si la aplicación del Derecho -per setiene un componente de arbitrariedad indiscutible, ¿cómo podemos seguir impasibles ante un conflicto tan problemático como lo son las enfermedades terminales a las que ni siquiera se les reconoce el derecho personal a decidir?

Veámoslo de la siguiente manera. El Derecho español no obliga a las personas a alargar y empeorar situaciones indignas y no deseadas por ellas, sino que procura su mejor derecho a la salud. Pero hemos olvidado en él, que el enfermo tiene derecho a estarlo y a decidir cómo consumir el final de su vida, si no puede procurársele una mejor salud: decidir continuar o no continuar.

No hay regulación al respecto en el Estado español, pero siguen llegando casos a los Tribunales de Justicia en busca de una resolución que pueda ejecutar un deseo unilateral, una voluntad personal, nacida de los propios Derechos fundamentales y de los Principios Generales del Derecho.

El derecho a una muerte digna nunca debería ser comparado o asimilado al suicidio, ya que a todas luces el derecho a decidir o elegir, necesita de un proceso jurídico y médico previo que nada tiene que ver con la voluntad unilateral sin proceso alguno. Considerar como suicidio asistido, a la eutanasia o al derecho a decidir cómo morir -en los casos susceptibles de ello-, jurídicamente sería un error. La ética personal de cada ciudadano, dictaminará si considera a ambos conceptos como iguales. Pero el Derecho no puede prestarse ni a compararlo, ni siquiera a asimilarlo. El suicidio no cuenta en absoluto con el reconocimiento del Derecho. La regulación de la muerte digna -por el hecho de ser norma jurídica-, implica el reconocimiento de la sociedad donde será aplicable. Regular el suicidio sería absurdo por la propia esencia del mismo: no tiene en cuenta más que la

24 Catedrático de Derecho Mercantil en la Universidad Autónoma de Barcelona. Abogado y profesor universitario. Conferencia: "Panorama actual del Derecho Marítimo Español". Facultad de Derecho de la Universidad de Sevilla. 29 de Septiembre de 2016. 
única voluntad de quien lo realiza, sin contar en absoluto con otras voluntades reconocidas por su sociedad.

Holanda despenalizó a los equipos médicos que aplicaban la eutanasia a partir de 1993: nueve años más tarde se legisló, regularizándose esta actividad. En la actualidad -octubre 2016- el Gobierno holandés tiene la intención de ampliar dicha norma, en vista del considerable aumento de solicitudes de personas que padecen grandes depresiones provocadas fundamentalmente por el sufrimiento psicológico ${ }^{25}$ : entre otras razones motivado por la soledad. Esta nueva regulación se enfrenta al dictamen desfavorable del Comité de especialistas al que se le encargó.

Con buen criterio habremos de ser muy cuidadosos en la permisibilidad normativa, pues en gran cantidad de ocasiones los "avances" pueden hacernos olvidar los "límites".

Asumiendo el estudio bajo el prisma del derecho comparado, deducimos la responsabilidad que nuestro sistema jurídico tiene por cubrir ante estas situaciones. Debiendo comenzar por el reconocimiento de las consecuencias de la quiebra del derecho a la salud -en algunas personas-, y continuando por el camino de la regulación normativa, de un derecho sin respaldo jurídico alguno.

\section{BIBLIOGRAFÍA CITADA}

- Abellán Salort, J.C. Fines y límites del Estado: paternalismo y libertades individuales. Universidad Francisco de Vitoria. Madrid. Anuario jurídico y Económico Escurialense XXXIX (2006) 363-384 / ISSN: 1133-3677.

- Boladeras, M. Bioética: La toma de decisiones. Editorial Proteus. 1aㅡ edición: octubre 2011.

- De Rotterdam, E. Elogio a la locura. Capítulo XIII. 1511.

- Declaración Universal de Derechos Humanos. Adoptada y proclamada por la Asamblea General en su resolución 217 A (III), de 10 de diciembre de 1948.

- Jakobs, G. Derecho Penal del Enemigo. Cuadernos Civitas, Thomsom-Civitas, 1ª edición: 2003.

- Lasarte, C. Derecho de Obligaciones II. Principios de Derecho Civil II. Decimonovena edición. Editorial Marcial Pons. Madrid 2015.

\footnotetext{
${ }^{25}$ De rabiosa actualidad a la fecha de la redacción de este artículo, encontramos la desesperación de una madre española (Olula del Río - Almería) que pide ayuda desesperada a los medios de comunicación, porque su hijo de 12 años -Alejandro- "quiere quitarse la vida", siendo acosado en el colegio desde los 8 años. Un sufrimiento psicológico que pronto puede verse regulado en países como Holanda.
} 
- Memento Práctico Francis Lefebvre. Acceso a la Abogacía. 2013-2014. Universidad Pontificia de Comillas. Ediciones Francis Lefebvre, S.A. Julio 2013. Madrid.

- Vero, Marco Aurelio. Meditaciones. Editorial Cátedra. Letras universales. $3^{\mathrm{a}}$ edición: 2005. Madrid.

Referencias:

- http://deportes.elpais.com/deportes/2016/08/15/actualidad/1471268175_36 3552.html (Deportista paralímpica belga solicita eutanasia tras olimpiadas).

- http://www.bbc.com/mundo/noticias/2015/10/151001_espana_muerte_dign a_nina_lav (Caso: Andrea Lago Ordóñez. Menor española. Sus padres solicitaron la eutanasia. España, octubre 2015).

- https://es.wikipedia.org/wiki/Erasmo_de_R\%C3\%B3terdam (Erasmo de Rotterdam).

- http://elpais.com/elpais/2016/10/15/opinion/1476560927_380583.html

- http://cadenaser.com/ser/2016/10/17/sociedad/1476697762_418954.html 